\title{
Fragmentos de um discurso criativo: notas para uma metodologia de composição da história
}

\author{
A creative's discourse fragments: notes for a methodology of story composition
}

\author{
MARCELO MALDONADO CRUZ* \\ Pontifícia Universidade Católica do Rio Grande do Sul, Porto Alegre, RS, Brasil
}

\begin{abstract}
Resumo: Resultado de uma antiga necessidade de efabulação, o processo de contar uma história requer do criador uma capacidade específica de reunir elementos da vivência humana e dar-lhes um significado maior através da dramatização. No entanto, uma história não surge na mente de um autor em sua forma acabada, mas, sim, aos pedaços, em fragmentos. Tal como o enamorado, no discurso amoroso de Roland Barthes, às voltas com o objeto de sua paixão, o autor promove uma intensa investigação acerca dos elementos constitutivos da história que quer contar, valendo-se muitas vezes de uma estrutura mítica para coordená-los. Este ensaio reúne algumas anotações para uma metodologia do processo criativo, desde a concepção da ideia original até a fase de estruturação da história, através da análise de alguns princípios básicos e conceitos norteadores como "lei do conflito", "princípio da progressão", "forças do antagonismo", "jornada do herói", entre outros.
\end{abstract}

Palavras-chave: escrita criativa; processo de criação; mito; imaginário.

\begin{abstract}
As a result of an ancient human need, the process of telling a story requires a specific ability to gather elements of human experience and give them a greater significance through the drama. However, a story does not arise in the mind of an author in its finished form, but in pieces or fragments. As in "A lover's discourse: fragments", by Roland Barthes, seduced by the object of his passion, the author promotes an intense investigation into the constituent elements of the story he wants to tell, often using a mythic structure to coordinate them. This essay presents notes for a methodology of the creative process, from the conception of the original idea to the structuring phase of the story, by analyzing some basic principles and guiding concepts such as "conflict law", "progression principle", "forces of antagonism", "hero's journey", among others.
\end{abstract}

Keywords: creative writing; creation process; myth; imaginary.

\footnotetext{
* Mestre em Letras (Escrita Criativa), Pontifícia Universidade Católica do Rio Grande do Sul (PUCRS). Bolsista CNPq. <marcelo.cruz@acad.pucrs.br>.
} 
À guisa de manual de leitura para o bastante incomum volume intitulado Fragmentos de um discurso amoroso, à época de sua publicação, Roland Barthes (1994, p.1) afirmava a necessidade de se devolver o discurso amoroso à sua característica de enunciação, pondo em cena, isto é, no lugar de fala, o próprio ser amoroso, o apaixonado, cujo debater-se com a linguagem para tratar de seu tema (o ser amado) seria empreendido em constantes idas e vindas, "démarches", "intrigas".

O criador, por sua vez, qual o enamorado que corre para todo lado em sua cabeça, sempre diligente, tecendo intrigas contra si próprio, exerce o discurso criativo através de "lufadas de linguagem, que lhe vêm no decorrer de circunstâncias ínfimas, aleatórias" (BARTHES, 1994, p.1). Essas lufadas - ou frações de discurso, a que Barthes vai denominar figuras - ora têm o poder de impulsionar a embarcação capitaneada por ele para distâncias além, jamais imaginadas ou apenas vislumbradas, ora sequer o auxiliam a romper a calmaria de águas estagnadas. Barthes confere ao termo figura um sentido que foge do entendimento retórico e recai numa concepção ginástica ou coreográfica.

... enfim, no sentido grego: $\sigma \chi \eta \mu \alpha$, não é o "esquema"; é, de uma maneira muito mais viva, o gesto do corpo captado na ação, e não contemplado no repouso: o corpo dos atletas, dos oradores, das estátuas: aquilo que é possível imobilizar do corpo tensionado. Assim é o enamorado apressado por suas figuras: ele se debate num esporte meio louco, se desgasta como o atleta; fraseia como o orador; é captado, siderado num desempenho, como uma estátua. A figura, é o enamorado em ação. (BARTHES, 1994, p. 1).
Pensar o processo criativo significa, para o próprio criador, reconhecer em suas figuras as múltiplas inferências e referências responsáveis pela sua formulação e, com isso, recapitular (ou recapturar) o instante em que essas lufadas adquiriram um espírito gregário, um sentido para além de uma abstração e rumo a uma representação. Não é partir da obra em si para decupá-la em unidades estruturais e compreender o seu funcionamento. Significa retroceder ao instante da explosão das figuras (em imagens, em ideias) e de sua vibração em forma de movimento para proceder a uma reflexão acerca de suas possibilidades significativas.

Muitos artistas descrevem a criação como um percurso do caos ao cosmos. Um acúmulo de ideias, planos e possibilidades que vão sendo selecionados e combinados. As combinações são, por sua vez, testadas e assim opções são feitas e um objeto com organização própria é construído desse anseio por uma forma de organização. (SALLES, 2013, p. 41).

A esse respeito cabe, aqui, transcrever uma reflexão rabiscada num caderno de notas, feita em 31 de janeiro de 2015: A história é uma massa. Ela surge fragmentada, em pedaços, sem rumo, à deriva no tempo e espaço, sem grandes delineamentos. Como os aspectos técnicos da escritura (vistos como uma receita de bolo?) agregam os pedaços soltos da história e criam um sentido maior? Como, por exemplo, delinear conflitos filosóficos/ontológicos importantes (dor / solidão / paixão / loucura etc) através da manipulação dos fragmentos da história dentro das técnicas de escritura e demais processos de forma a moldar um todo coeso e coerente? 
Com muito mais questões do que revelações, tanto quanto o próprio movimento criador, o pensar acerca do processo criativo constitui-se num evento solitário. Tanto mais se comparado à solidão de que nos fala Barthes a respeito do discurso amoroso. Embora praticado por milhares de criadores que, nas tentativas de composição de suas obras, enfrentam idas e vindas constantes, por muito tempo não foi sustentado pelas linguagens que endossam o aparato de poder do conhecimento e seu ingresso no ambiente acadêmico como objeto de estudo deu-se apenas a partir de uma conjuntura de fatores que propiciou o surgimento da crítica genética, em fins dos anos 1960, na França.

Com um rétard de cerca de 20 anos, a crítica genética chegou ao Brasil, primeiramente via Universidade de São Paulo, em meados dos anos 1980, e teve seus limites de atuação estendidos com a criação do Centro de Estudos de Crítica Genética em 1993, na Pontifícia Universidade Católica de São Paulo. Debruçados sobre os "documentos de processo" (manuscritos, diários, cartas, rascunhos, cadernos de notas etc), os pesquisadores passaram a compreender melhor os mecanismos de produção de uma obra artística.

Se a obra de arte é tomada sob a perspectiva do processo, que envolve sua construção, está implícito já na própria ideia de documento o conceito de trabalho. Os vestígios podem variar de materialidade, mas sempre estarão cumprindo o papel indiciador desse processo e, como consequência, do trabalho artístico. (SALLES, 2013, p. 25).

É possível, neste ponto, fazer uma analogia entre a tarefa executada pelo enunciador do discurso amoroso proposto por Barthes e aquela a que se pretende o estudioso dos aspectos do processo criativo: a de tentar transpor a solidão na qual se desenvolve o ato criador e percorrer os seus múltiplos meandros, os caminhos repletos démarches e intrigas que constituem seus processos experimentais e que conduzem à concretização de uma determinada obra. Ora, isso só é possível quando o criador fornece rastros, pistas, documentos a partir dos quais se pode refazer as idas e vindas e, por conseguinte, mapear as escolhas que o conduziram da concepção da ideia à obra (supostamente) terminada.

Aqui, no entanto, tal como pretende Barthes em seu livro-ensaio (e livre ensaio, pois), trata-se de se devolver à cena o próprio articulante do discurso criativo a fim de que se torne o primeiro a apontar e/ou descrever as diversas etapas percorridas no processo de transformação deste discurso em obra. Para tal, a forma (e não fórmula) adotada foi semelhante: em lufadas de linguagem, figuras, cenas, verbetes, enfim, fragmentos, tento recuperar o prazer e o encantamento de lidar com um universo dentro do qual orbitam serem tão distintos quanto diversos, aos quais procura-se dar vida.

\section{Começo com um formigamento}

IDEIA. Momento de lucidez, em meio ao caótico fluxo contínuo do pensamento, em que algo se adensa, destaca-se e, dotado de animação própria, reclama para si ações e desdobramentos.

1.1 Isak Dinesen costumava dizer: "Começo com um formigamento, uma certa intuição acerca da história que vou escrever. Depois vêm as personagens, e elas assumem o controle, fazem a história" (DINESEN, 1976 apud KOCH, 2008, p. 3). 
Vladimir Nabokov (citado por $\mathrm{KOCH}$, 2008, p. 3) por sua vez, sugeria algo como uma pulsação. Ou um vislumbre. Isabel Allende localiza a história "num lugar muito sombrio e secreto ao qual ainda não tenho acesso. É algo que venho sentindo, mas que não tem forma, nem nome, nem som, nem voz" (ALLENDE, 1983 apud KOCH, 2008, p. 5, 6). Muito semelhante à reflexão que anotei em meu caderno: A história é uma massa. Ela surge fragmentada, em pedaços, sem rumo, à deriva no tempo e espaço, sem grandes delineamentos.

1.2 Big Bang e Geleia Geral. Numa das primeiras aulas do curso de mestrado em Escrita Criativa, na PUCRS, o professor Luiz Antonio de Assis Brasil aludiu a esses termos para tornar reconhecíveis as duas principais manifestações de uma ideia, numa mente criadora. Revejo as minhas anotações e lá encontro: Big Bang Explosão - singularidade pela qual a ideia se dá - surge originalmente difusa, mas guarda uma precisão. Não posso me furtar a identificar essa definição com o que propõe Nabokov a respeito da pulsação ou do lampejo. A continuidade das anotações de aula me traz a segunda manifestação: Há uma névoa, uma "geleia geral" que sugere um algo a ser escrito, que se organiza e se encaminha para uma sistematização. Desta vez reconheço a similaridade com as reflexões de Isabel Allende e com minhas próprias considerações acerca da história.

\section{O gato no tapete do cachorro}

HISTÓRIA. Aquela mágica que se realizava em volta do fogo para que os homens da pré-história vencessem o medo da grande noite. Aquilo que, hoje em dia, se costuma contar para o chefe a fim de justificar o atraso ao trabalho (ou para o orientador, com vistas a estender o prazo para entrega da dissertação).

\subsection{No prefácio a Roderick Hudson, Henry} James assinala que, após reconhecida a ideia do romance, sobreveio-lhe o temor dos desenvolvimentos: "Estes são da própria essência do processo do romancista e é fundamentalmente por meio deles que a ideia toma forma e vive, ainda que imponham ao artista, graças ao princípio da continuidade que os conduz, uma ansiedade proporcional" (JAMES, 2003, p. 115). O desenvolvimento de uma ideia em história implica na tessitura de uma intrincada rede de relações cujo principal (e refinado) problema para o artista, segundo James, consiste em "traçar, por uma geometria própria, o círculo dentro do qual elas parecem com felicidade fazê-lo" (JAMES, 2003, p. 116).

\subsection{Recorro novamente às minhas} anotações de aula e verifico que lá está, em outras palavras, o mesmíssimo dilema: o escritor cria um micromundo, da sua gênese ao apocalipse. No continuum da vida, dentro desse universo criado, cabeIhe selecionar dois pontos que assinalam a partida e a chegada de sua história, que se estabelecem num todo organizado por relações de causa e efeito - e aqui cabe uma distinção feita pelo professor: mesmo numa história fragmentada, o que se fragmenta é a forma e não o conteúdo. Os fragmentos são sempre organizados de maneira a formar um todo coerente (assim como neste ensaio).

2.3 O trabalho de retomada da origem, do momento em que a ideia - imersa na geleia ou revelada pelo lampejo - 
tomou um molde distinto, é o que vai dar ao criador o sentido da história e, consequentemente, a primeira pista para a sistematização dessa história num todo orgânico. Essa origem determinará que tipo de estrutura vai dar forma à história, como ela se organizará, porque deflagra, em seu cerne, uma unidade de conflito.

2.4 Stephen Koch (2008) argumenta que a chave para qualquer história é o conflito. "O gato deitou no tapete", como diz [John] Le Carré, "não é o começo de uma história, mas 'O gato deitou no tapete do cachorro', sim" (KOCH, 2008, p. 98). Robert McKee (2006) estabelece uma Lei do Conflito e Ihe confere uma importância que vai além do princípio estético, denominando-a a própria alma da história.

A estória é uma metáfora para a vida, e viver é estar num conflito aparentemente perpétuo. Como JeanPaul Sartre expressou, a essência da realidade é a escassez, uma falta eterna e universal. Nada é suficiente nesse mundo. Não há comida o suficiente, amor o suficiente, justiça o suficiente, e nunca tempo o suficiente. Tempo, como Heidegger observou, é a categoria básica da existência. Vivemos sob sua sombra, que sempre está encolhendo, e se conseguirmos alcançar qualquer coisa em nossa breve existência que nos deixe morrer sem o sentimento de que desperdiçamos nosso tempo, teremos de entrar de cabeça em conflitos com as forças da escassez que negam os nossos desejos. (MCKEE, 2006, p. 203).

2.5 Ainda sobre Sartre, revejo em anotação de aula o seguinte: $\mathrm{O}$ drama do ser humano contingente e o quanto ele se reconhece em si mesmo - É através da consciência humana que a matéria se reconhece e, como tal, sabe-se finita. Um ser sobre o qual, assim como na vida, recai a consciência do conflito. E que, numa história, vamos denominar personagem.

\section{Character is plot}

PERSONAGEM. Núcleo da unidade de conflito. Indivíduo existente em estado de drama. Em cem por cento das vezes, é a respeito de quem as crianças interrompem a narração de uma história para perguntar se é bom ou mau.

3.1. De fato, uma vez que só pode existir em estado de drama (no sentido dado pela origem grega, ação), a personagem é a responsável por mover adiante a história, acionar a rede de relações de causa e efeito sobre a qual se estrutura o continuum da vida, dentro do micromundo fabricado pelo criador. Dotada de um desejo, de uma vontade, a personagem é o ser sobre o qual recai a consciência da escassez, de que nos fala Sartre, o que faz com que, a partir dessa percepção, aja no sentido de buscar o que Ihe falta.

\subsection{Renata Pallottini (2013) retoma o} conceito hegeliano de personagem:

Ora, é essa pessoa moral, em ação, em última análise, a personagem para Hegel; em ação porque dinâmica, porque fazendo que se cumpram, no drama, sua vontade livre, sua escolha, suas opções, seus sentimentos e suas paixões; pessoa moral que é o ser humano em sua plenitude, em seu relacionamento com os outros homens e com o mundo, com suas crenças, convicções, ética, princípios, mas também falhas e dúvidas. (PALLOTTINI, 2013, p. 43).

3.3 Minhas anotações de sala de aula complementam: As contradições lógicas fazem parte do universo da personagem para torná-la convincente. [A personagem 
deve ser] Dotada de uma vontade, de uma intenção. [A personagem] Deve simular uma presença consistente e que dê ao leitor a impressão de que tudo decorre do fato dela existir. Essas notas encontram eco nas reflexões de Robert McKee referentes à função da personagem, que, segundo ele...

(...) é trazer à estória qualidades de caracterização necessárias para fazer escolhas convincentes. De forma simples, um personagem deve ser crível: jovem o suficiente ou velho o suficiente, forte ou fraco, mundano ou ingênuo, educado ou ignorante, generoso ou egoísta, esperto ou bobo, nas proporções certas. A combinação de qualidades deve permitir que o público acredito que o personagem poderia agir, e agiria, de maneira que age nas tela. (MCKEE, 2006, p. 110).

3.4 Pallottini, por sua vez, arremata: "Os acontecimentos do drama, diz o filósofo, não devem parecer fruto de fatos exteriores, mas sim da vontade das personagens. É o seu caráter, são os fins que esse caráter persegue que dão sentido à ação, que a motivam" (PALLOTTINI, 2013, p. 43).

O melhor modo de desenvolver uma personagem é, sem dúvida, contar a história dela. E o melhor modo de desenvolver uma história é, com toda a certeza, contar o que suas personagens fazem. Afinal, as histórias são o que as personagens fazem, e as personagens são o que elas fazem nas histórias. Diferentemente dos seres humanos, as personagens não têm vida fora das páginas. $(\mathrm{KOCH}, 2008$, p. 111).

3.5 Syd Field (2001), em seu Manual do roteiro, ensina:

Primeiro, estabeleça o personagem principal. Depois separe os componentes da vida dele/dela em duas categorias básicas: interior e exterior. A vida interior do seu personagem começa desde o nascimento até o momento em que o filme começa. É um processo que forma o personagem. A vida exterior do seu personagem acontece desde o momento em que o filme começa até a conclusão da história. É um processo que revela o personagem. (FIELD, 2001, p. 19).

3.6 Encontrar a voz da personagem. Esse foi um dos tópicos de uma das aulas do Assis, que gerou 7 etapas/questões básicas para auxiliar nessa tarefa:

a) Listar 3 ou 4 coisas que a personagem mais valoriza;

b) Listar 3 ou 4 coisas que a personagem mais teme;

c) $\mathrm{O}$ que a personagem considera como a melhor coisa que pode the acontecer?

d) $\mathrm{O}$ que a personagem considera como a melhor qualidade a ser encontrada nas outras pessoas?

e) Em quais características a personagem é conservadora?

f) Em quais características a personagem é progressista?

g) Como a personagem é vista pelas outras pessoas?

\section{Afinal de contas, o que diabos você quer?}

DESEJO. Quero que todos os dias do ano / todos os dias da vida / de meia em meia hora / de 5 em 5 minutos / me digas: Eu te amo. ${ }^{1}$

4.1 É necessária uma pausa para acompanhar o desenvolvimento da ideia até o presente estágio:

\footnotetext{
1 ANDRADE, Carlos Drummond de. Quero. In: impurezas do branco. São Paulo: Companhia das Letras, 2012. p. 44
} 
a) Surgimento da ideia: em sua forma embrionária, tem-se a constituição de um núcleo dramático através da sugestão de uma cena dada por um processo de indução (Big Bang / Geleia geral), e, portanto, conotativo.

b) Esse núcleo é composto por uma personagem, seu conflito e meta iniciais, matérias primas a partir das quais o criador será capaz de construir um universo ficcional distinto, ao proceder de acordo com um método de dedução, ou, ainda, denotativo.

c) Esse procedimento é o responsável pelo conjunto de perguntas e hipóteses que norteou os dados acerca da personalidade, das motivações psicológicas e antecedentes biográficos da personagem principal. As respostas a essas questões também serviram de base para moldar a rede de relações estabelecidas em decorrência da interação dela com as demais personagens.

d) A expansão do nível de complexidade dessa rede de relações contribui para a construção do sentido da história e de seus desdobramentos.

4.2 A partir da personagem principal, do seu conflito e meta iniciais, as demais personagens vão surgindo e são desenvolvidas segundo o mesmo processo: enquanto organismos autônomos, dotados de antecedentes biográficos, motivações psicológicas, contradições lógicas, vontades e metas que devem se entrelaçar às do protagonista para gerar as tensões e conflitos imprescindíveis à progressão dramática da história.

4.3 As vontades, os desejos são o combustível vital para que as personagens se ponham em movimento, em busca de seus objetivos. Segundo McKee, "na busca de qualquer desejo, em qualquer momento da estória, [a personagem] sempre tomará a ação mínima, a mais conservativa no seu ponto de vista" (MCKEE, 2006, p. 142, grifo do autor). A ela cabe a decisão que, de acordo com o seu modo de agir e pensar, Ihe permitirá obter aquilo que deseja da maneira mais eficiente e sob o menor dispêndio de energia. Porém, "em vez disso, o efeito de sua ação é provocar as forças do antagonismo. O mundo do personagem reage diferente do esperado, ou mais poderosamente do que o esperado ou ambos" (MCKEE, 2006, p. 143).

4.4 Há sempre uma brecha que se abre entre as atitudes que as personagens tomam para conseguir aquilo que querem e a resposta a essas ações. Os desejos da personagem tornam-se tão mais complexos (e por vezes desconhecidos para si mesma) quanto mais profundo for o entrelaçamento entre as suas vontades e as das personagens com as quais ela interage. Muito mais do que coincidências, esse entrelaçamento vai provocar divergências que estabelecem uma tensão crescente nessas relações e, consequentemente, aprofundam os conflitos de cada uma das partes envolvidas.

\subsection{Segundo Robert McKee (2006,} p. 144), existem três níveis de manifestação do conflito:

a) Interno - deflagrado pelo fluxo de consciência e pelas questões com as quais a personagem se debate em seu íntimo, com as emoções e o próprio corpo;

b) Pessoal - deflagrado pelas relações diretas com as demais personagens de um dado universo, com as quais 
é preciso uma negociação para se que se resolvam diferenças (família, amantes, amigos);

c) Extrapessoal - deflagrado pelas dificuldades causadas por um ambiente físico hostil e inóspito ou pela impessoalidade das instituições.

4.6 Da mesma forma, os desejos e vontades das personagens se organizam conforme os níveis de conflito que elas experimentam. Dadas as múltiplas e complexas formas de organização da natureza e da mente humanas, ao lidar com os conflitos em seus diferentes níveis, as personagens se equivocam quanto aos próprios desejos e objetivos. Não raro tomam atitudes que as afastam daquilo que julgam ser a sua meta principal. É muito comum que vontades e desejos não se configurem com muita nitidez dentro das percepções das personagens, o que causa hesitação, dúvidas e o medo de agir. Por outras vezes, aquilo que a personagem quer não é exatamente do que ela precisa para seguir adiante, transpor um obstáculo ou amadurecer.

4.7 Todas essas falhas de percepção, de comunicação e de conhecimento são importantes no desenvolvimento da progressão de uma história, pois que geram tensões entre as personagens e provocam as forças do antagonismo, como definiu Robert McKee (2006, p. 146). Há sempre um acontecimento, um incidente (de ordem interna, pessoal ou extra pessoal) que provoca a personagem a buscar aquilo do que ela sente falta para restaurar o equilíbrio do seu cotidiano. Ao tentar uma ação conservativa, a personagem aciona as forças do antagonismo, que, por sua vez, respondem de forma a aumentar o grau de dificuldade para o cumprimento da tarefa. Uma brecha se abre. A personagem terá, então, de empreender uma nova ação, um pouco mais arriscada do que a anterior, para conseguir alcançar a sua meta. É o princípio da progressão em ação.

4.8 Tramar as urdiduras entre esses níveis de conflitos de uma personagem e relacioná-las com os correspondentes existentes nas demais personagens é o que enriquece as possibilidades de significação e, portanto, de leitura de uma obra. É o que vai gerar cenas de grande força dramática, capazes de mover adiante a história.

\section{O esqueleto no armário}

ESTRUTURA. Conjunto formado, natural ou artificialmente, pela reunião de partes ou elementos, em determinada ordem ou organização. A minha dificuldade em terminar de montar as 5 mil peças daquele quebra-cabeças de uma paisagem dos alpes suíços.

5.1 Conflitos geram desejos / Desejos geram ações / Ações geram consequências / Consequências geram mudanças / Mudanças geram novos conflitos / Novos conflitos geram novos desejos (ou o reforço do querer original) / Novos desejos geram novas ações... ad aeternum.

5.2 Este é o ciclo da história. Os eventos são gerados por uma força de natureza conflituosa, que, por sua vez, exige que uma ou mais atitudes sejam tomadas para solucioná-la. A cada novo evento, uma ação é requerida para resolver uma brecha deixada pela ação anterior. Esses eventos, selecionados e compostos "em uma sequência estratégica para estimular 
emoções específicas, e para expressar um ponto de vista específico" (MCKEE, 2006, p. 45), formam a estrutura da história.

\begin{abstract}
A função da ESTRUTURA é criar pressões progressivamente construídas que forcem o personagem a enfrentar dilemas cada vez mais difíceis, fazendo escolhas de risco e tomando atitudes cada vez mais difíceis, gradualmente revelando a sua verdadeira natureza, até mesmo chegando ao seu eu inconsciente. (MCKEE, 2006, p.110, grifo do autor).
\end{abstract}

5.3 Os eventos são expressos pelo que acontece na história, que, por conseguinte, é representado numa cena. "A cena é o elemento isolado mais importante de seu roteiro. É onde algo acontece - onde algo específico acontece. É uma unidade de ação - e o lugar em que você conta a sua história. (...) O propósito de uma cena é mover a história adiante (FIELD, 2001, p.112). A noção dinâmica da cena é dada pela intensidade com que os seus elementos causam uma mudança significativa nas vidas das personagens, em virtude de suas escolhas naquele determinado instante. Essa intensidade também deve se refletir nos seus efeitos sobre o público:

Mas as cenas não ficam estáticas; a intensidade dos sentimentos do espectador tem de aumentar e concentrar-se. Essa ideia de uma ação crescente envolvendo cada vez mais esperança e mais medo é a essência mesmo daquilo que mantém o público envolvido durante a história. (HOWARD e MABLEY, 1996, p.109, 110).

5.4 A criação das cenas segue a necessidade de se estabelecer os elos entre as personagens por meio de suas ações. No momento em que o criador tem em mãos os principais elementos de modo a montar a história de acordo com um todo organizado por relações de causa e efeito, dentro do continuum da vida do mundo criado, da gênese ao apocalipse, é a hora de transformar em ação dramática as vontades expressas pelas personagens.

5.5 Que elementos são esses? Personagens com vontades e metas; um ponto de partida para a trama e alguma intuição acerca de como deve terminar; o entrelaçamento das relações entre as personagens de modo a aprofundar os níveis de conflito e, com isso, gerar tensão o bastante para mover a história adiante, numa jornada particular.

\section{A jornada}

ARQUÉTIPO. Padrão, exemplar, modelo, protótipo. Termo utilizado pelos filósofos neoplatônicos (Plotino, por exemplo) para designar as ideias como modelos de todas as coisas existentes. $\mathrm{Na}$ Psicologia Analítica, corresponde à forma imaterial à qual os fenômenos psíquicos tendem a se moldar.

\subsection{Contar uma história é lidar com a} antiquíssima necessidade de efabulação do homem. É dar continuidade ao ancestral ofício de recolher toda a sabedoria vital de uma vivência profunda e moldá-la à forma de exemplos capazes de causar uma forte impressão e, ao mesmo tempo, de ser assimilados e passados adiante com facilidade.

6.2 Os mitos, por sua vez, são uma espécie de repositório primordial dessa vivência profunda, no qual jazem as experiências primordiais do homem em sua tentativa primeira de se organizar 
enquanto animal social para garantir a sobrevivência do grupo, ao mesmo tempo em que nele suscita a consciência de seu lugar no mundo e a necessidade de dar sentido aos fenômenos naturais.

Porque se dirige à essência das coisas e desperta no homem o sentimento de unidade com o universo, o mito é a palavra que dá sentido ao existir e, assim, aproxima-se do sagrado. Ao atingir a essencialidade da existência, o dizer mítico propicia a comunhão do homem com o mundo, coloca-o em contato com o Ser ou deixa-o disponível a tal contato. Nessa perspectiva, a linguagem atinge a sua dimensão essencial, conforme Heidegger, que consiste em sua capacidade de revelar a verdade do Ser. (MELLO, 2002, p. 31, 32).

6.3 O filósofo, sociólogo e antropólogo francês Gilbert Durand (2002), influenciado sobremaneira pela obra de Gaston Bachelard, filósofo da fenomenologia da imaginação que valorizava "a potência poética da imagem, da palavra que emerge do inconsciente coletivo, constituindo-se ao mesmo tempo como pensamento e linguagem" (MELLO, 2002, p.13), empreendeu uma profunda investigação a respeito da imaginação simbólica à luz da antropologia, a partir da qual os símbolos correspondem à "incessante troca que existe no nível do imaginário entre as pulsões subjetivas que emanam do meio cósmico e social" (DURAND, 2002, p. 41). Para Durand, o processo de simbolização é importante no tocante à relação do homem com questões fundamentais como a morte, a temporalidade, cabendo ao símbolo o poder de figurar essas noções de transcendência numa representação concreta, dando materialidade a um sentido por vezes secreto, misterioso e/ou abstrato.
6.4 A linguagem vai se tornar a instância organizadora das experiências sensoriais desse homem primitivo em sua rede de interações com o mundo físico, codificando-as em função de uma realidade fundadora e capaz de se perpetuar em sua exemplaridade. Ora, isso só é possível na medida em que a linguagem inaugura a forma narrativa, como, de fato, elucida Durand: "Entenderemos por mito um sistema dinâmico de símbolos, arquétipos e esquemas, sistema dinâmico que, sob o impulso de um esquema, tende a compor-se em narrativa" (DURAND, 2002, p.62,63). E Eliade complementa:

O mito conta uma história sagrada; ele relata um acontecimento ocorrido no tempo primordial, o tempo fabuloso do "princípio". Em outros termos, o mito narra como, graças às façanhas dos Entes Sobrenaturais, uma realidade passou a existir, seja uma realidade total, o Cosmo, ou apenas um fragmento: uma ilha, uma espécie vegetal, um comportamento humano, uma instituição. É sempre, portanto, a narrativa de uma "criação": ele relata de que modo algo foi produzido e começou a ser. (...). Os mitos revelam, portanto, sua atividade criadora e desvendam a sacralidade (ou simplesmente a "sobrenaturalidade") de suas obras. Em suma, os mitos descrevem as diversas, e algumas vezes dramáticas, irrupções do sagrado (ou do "sobrenatural") no Mundo. É essa irrupção do sagrado que realmente fundamenta o Mundo e o converte no que é hoje. E mais: é em razão das intervenções dos Entes Sobrenaturais que o homem é o que é hoje, um ser mortal, sexuado e cultural. (ELIADE, 1972, p. 9).

6.5 Para fazer sentido em sua figuração mais significativa, essa narrativa estruturase numa lógica na qual a realidade é representada a partir de imagens nascidas 
no seio da coletividade e que encerram em si características de uma determinada experiência primordial: maternidade, nascimento, morte etc. São os arquétipos. "No mito, o molde arquetípico manifestase em imagens simbólicas, provenientes da psique coletiva" (MELLO, 2002, p. 37).

\subsection{Carl Gustav Jung foi o principal} articulador do conceito de inconsciente coletivo, do qual o arquétipo, enquanto unidade básica da psique humana (e, portanto, irredutível), faz parte e funciona como uma espécie de modelo, padrão das experiências existenciais. Segundo Ángel Zapata:

De acuerdo con Jung, nuestro pensamiento dirigido está orientado hacia fuera, hacia los objetos y el mundo exterior. Se desarrolla por medio de las palabras, y tiene un carácter principalmente social (de hecho, cuando empleamos este tipo de pensamiento, hablamos con nosotros mismos como le hablaríamos a otra persona). El pensamiento dirigido, pues, copia la realidad, sus leyes, sus relaciones, y tiene como fin actuar sobre ella. (...) Pero al lado de esta actividad mental volcada hacia las cosas, hacia lo real, Jung detecta otra clase de pensamiento diferente: el pensamiento fantaseador. Orientado hacia dentro, hacia las tendencias y los deseos subjetivos, el pensamiento fantaseador no maneja tanto conceptos y palabras, como puras imágenes. Funciona con contenidos inconscientes y motivos caprichosos e inventados. Se desarrolla en nosotros de una manera involuntaria y no requiere esfuerzo alguno. No tiene como función adaptarse a la realidad ni actuar sobre ella, sino liberar deseos, fantasías, invenciones de todo tipo. Tampoco nos proporciona una imagen objetiva de las cosas - como el pensamiento dirigido -; y no obedece a la lógica, sino a la mera asociación de ideas. (ZAPATA, 1997, p. 204).

\subsection{David Sheppard (2009) acrescenta:}

These archetypal images come and go of their own will and are transcendent to the world of sense. Archetypes are viewed as the primary forms that govern the psyche, and thus, archetypal psychology is linked with culture and the imagination, rather than the medical and empirical psychologies of Freud and Jung. (...) This is of crucial importance to the novelsmith because to glimpse an imagined reality, which is exactly what he does during the creation of stories that are all actually myths, requires methods and perceptual faculties different from those used to see the sensual world. The writer must become sensitive to the imagined realities emanating from the collective unconscious and develop the skills to handle them. (SHEPPARD, 2009, p. 159, 160).

\subsection{O norte-americano Joseph Camp-} bell, um aficionado pelas questões relativas às religiões e aos mitos, após anos imerso nos estudos das culturas nativas americanas, dedicou-se às teorias de Jung e, inspirado por elas, escreveu O herói de mil faces, obra em que analisa o mito do herói e o articula em termos narrativos de acordo com a jornada que ele realiza em prol de seus objetivos, através de diversos e bem definidos estágios. Outros arquétipos, reconhecidos por Campbell (2005), juntam-se ao herói nessa jornada: mentores (ou sábios), arautos, aliados, pícaros (ou bufões), vilões ou sombras entrelaçam seus próprios destinos aos dele, cada qual buscando, igualmente, um objetivo próprio.

6.9 Christopher Vogler (2015) adaptou as ideias de Campbell ao que chamou a Jornada do escritor: um guia de elementos formadores da narrativa para escritores. 
"O conceito de arquétipo é uma ferramenta indispensável para entender o objetivo e a função dos personagens em uma história. A compreensão do arquétipo que um personagem específico expressa pode ajudar a determinar se o personagem está fazendo sua parte a contento na história. Os arquétipos são parte da linguagem universal da narrativa, e um domínio de sua energia é tão essencial para o escritor como respirar. (VOGLER, 2015, p. 62).

6.10 A principal percepção, nesse processo, consiste em não considerar os arquétipos como papéis rígidos a serem desempenhados pelas personagens da narrativa, mas como funções que eles ocupam por um determinado tempo com a finalidade de alcançar um determinado objetivo ou efeito. Ou, ainda, como facetas de uma mesma personalidade. Afinal de contas, do ponto de vista de um vilão, ele é o herói de sua própria jornada.

Olhar para os arquétipos dessa forma, como funções flexíveis de caráter em vez de personagens rígidos, pode liberar sua arte da narrativa. Essa visão explica como um personagem numa história pode manifestar as qualidades de mais de um arquétipo. Os arquétipos podem ser pensados como máscaras, usadas pelos personagens temporariamente, quando a história precisa avançar (VOGLER, 2015, p.62, 63).

6.11 Em seu livro, Vogler descreve as características gerais dos principais arquétipos que empreendem a jornada do herói e adapta para o número de 12 os diversos estágios especificados anteriormente por Campbell.

6.12 Os principais arquétipos (e suas características resumidas) da jornada do herói são: a) Herói: aquele que se dispõe a sacrificar-se para suprir as necessidades de outrem ou atingir um objetivo específico. Em termos psicológicos, é o EU, o ego, e representa a busca da própria identidade. Sua função dramática é a de portar o conflito da história e, com isso, mover adiante a narrativa. Com isso, ele é aquele capaz de captar a simpatia do leitor ou do público, que passa a torcer para o seu sucesso. Outra função do herói é a de crescimento (amadurecimento). Em sua jornada, os heróis agem, lidam com a morte, expõem-se a perigos, têm defeitos e falhas, frequentemente recusam à primeira vista a missão dada, podem ser gregários ou solitários e até mesmo anti-heroicos.

b) Mentor (velho ou velha sábios): aquele serve de orientador ou referência para o herói. Geralmente oferece presentes, amuletos ou conselhos para auxiliá-lo em sua tarefa. Sua função psicológica é a de representar o self, simbolizando um espelho daquilo que o herói pode atingir se persistir na jornada. Geralmente confunde-se com as imagens paterna e materna. Sua função dramática é a do ensinamento, preparação ou treinamento para a jornada.

c) Guardião de limiar: representa um obstáculo pelo qual o herói precisa passar para avançar na jornada. Pode ser físico ou imaterial, pode representar pessoas, fenômenos naturais ou fobias internas. Por isso, sua função psicológica é comumente atrelada às neuroses, enquanto sua 
função dramática é a de testar a vontade do herói.

d) Arauto: aquele que anuncia os ventos da mudança. Pode, da mesma maneira, tanto ser uma pessoa quanto um mero acontecimento capaz de comunicar ao herói que definitivamente chegou a hora de agir. Por esse motivo, sua função psicológica é a de um chamado à mudança, ao passo que sua função dramática é a de motivação à ação.

e) Camaleão: aquele que se esconde sob um manto de mistério e incerteza. Em geral, uma pessoa ou uma circunstância na qual o herói não se sente seguro para confiar e que pode mudar de configuração a qualquer instante. A função do camaleão está ligada aos conceitos de animus e anima, de Jung, que se referem à presença de características masculinas e femininas no inconsciente das personagens. A função dramática do camaleão é a de trazer dúvida e incerteza à narrativa.

f) Sombra: muitas vezes identificada como o vilão contra o qual o herói precisa lutar para conseguir o que deseja, a sombra representa a energia do lado obscuro, o desconhecido, o insondável. Por isso, sua função psicológica é a de representar os sentimentos reprimidos, aquilo que pode destruir o ser quando mantido na escuridão do inconsciente. A função dramática da sombra é oferecer ao herói uma força significativa contra a qual lutar, sob o risco de ameaça à própria vida.

g) Aliado: pessoa, objeto ou circunstância que surge para auxiliar o herói a completar uma tarefa, decifrar um enigma, sair de uma situação difícil ou mesmo vencer as forças do antagonismo.

h) Pícaro: o alívio cômico. A energia travessa, alegre, o momento de distensão. Sua função psicológica de reduzir a seriedade, chamar a atenção para o risível, o absurdo, apontar a tolice e hipocrisia residentes nas demais personagens e em determinadas situações.

6.13 Quanto aos estágios da jornada, Vogler listou 12:

1) Mundo comum: em que se apresenta o herói em seu "mundo em equilíbrio", onde a necessidade da ação ainda não se faz presente, mas já se pode pressentir o que está por vir. É onde, da mesma forma, as questões com as quais o herói vai lidar já aparecem ainda que veladas, à espera de que algo ou um acontecimento específico as desencadeie. Geralmente é no ambiente do mundo comum que surgem detalhes a respeito da história pregressa do herói.

2) Chamado à aventura: é o incidente que desencadeia a consciência de que é preciso agir para colocar a história em movimento. Um desequilíbrio no mundo comum, uma mudança que exige do herói uma certa atitude, lançando-o, na maioria das vezes, num estado de desconforto, ansiedade e dúvida.

3) Recusa do chamado: diante da necessidade de agir, o herói se desorienta e se mostra indeciso, hesitante. Por uma série de expedientes, procura esquivar-se à missão que se apresenta à sua frente. 
4) Encontro com o mentor: é nesse estágio que o herói adquire a confiança necessária para se lançar à jornada, através do encontro com alguém geralmente mais velho e mais sábio ou com uma circunstância que the confere um conhecimento necessário para enfrentar as primeiras provações.

5) Travessia do primeiro limiar: o primeiro teste do herói. Aqui ele encontra seus oponentes iniciais, precisa decifrar algum enigma, dar conta de uma situação difícil ou lidar com as particularidades de um novo ambiente, o chamado mundo especial. $\mathrm{O}$ mundo especial é o mundo da aventura e difere do mundo comum porque, sobre ele, o herói possui pouco controle ou quase informação alguma, o que dificulta bastante a sua missão. Representa a passagem do primeiro para o segundo ato, numa narrativa.

6) Provas, aliados e inimigos: no processo de ambientação com o mundo especial, o herói encontra-se com os seus habitantes, faz amigos e inimigos, e tem de lidar com situações que lhe proporcionam novos testes.

7) Aproximação da caverna secreta: uma vez adaptado, o herói prossegue rumo ao âmago do mundo especial, numa viagem em que o aguardam novas provações. Aqui a preparação se torna primordial e o herói mune-se de todas as armas e conhecimentos de que dispõe até o momento para enfrentar o perigo.

8) A provação: o encontro do herói com a prova mais árdua até então. Desse encontro, o herói sai trans- formado por uma experiência de quase morte, representada pelo contato com as forças da sombra.

9) Recompensa: o herói tem um momento de descanso e celebração por ter sobrevivido à mais dura provação da jornada. Uma festa, risos ou um relacionamento romântico têm seu lugar nesse estágio. O herói recebe reconhecimento por suas qualidades, mas, ao mesmo tempo, tem a consciência de que o pior ainda está por vir.

10) O caminho de volta: sobreviver não é tudo. O herói precisa voltar para casa ou seguir adiante até o fim. Inicia-se, então, nova jornada. Significa outra travessia de limiar que, numa narrativa, marca a passagem do segundo para o terceiro ato. Em geral, as forças do antagonismo se intensificam e a perseguição ao herói torna-se mais intensa.

11) A ressurreição: como resultado desse assédio, o herói se confronta uma vez mais (e a derradeira) com as forças sombrias, o que Ihe vale uma nova experiência de quase morte. É a batalha final, a última cartada, o movimento mais ousado e arriscado para subjugar de uma vez por todas as forças do antagonismo. Dela, o herói sai consagrado ou derrotado. Significa o clímax da narrativa, onde o principal conflito é resolvido.

12) Retorno com o elixir: ao superar o desafio maior, o herói sofre uma última e irremediável transformação. Agora as marcas da jornada se fazem presentes nele e ele já não é mais o mesmo que era quando a iniciou. Ao retornar ao mundo comum, o herói traz consigo essas marcas, um 
elixir, um conhecimento, algo que vai compartilhar com aqueles que ficaram à sua espera. É o momento do desenlace da história, da resolução, dos destinos. É quando o herói encontra a recompensa ou a punição pelos seus atos ou quando, numa perspectiva em aberto para as questões levantadas, ele se vê diante da necessidade de mais uma jornada.

6.14 Grosso modo, os estágios da jornada, tais como apresentados por Campbell e Vogler, expressam as mesmas premissas e desenvolvimentos descritos anteriormente neste trabalho em termos de conflito, motivações, relações de causa e efeito, voz da personagem, organicidade etc.

6.15 Aplicar os princípios da jornada do herói na composição de uma história, antes de transformar as personagens em títeres, favorece um conhecimento mais profundo acerca de suas motivações, do como e por que são levadas a agir de determinada forma em dados momentos da história. De posse dessa nova consciência acerca de suas intenções e objetivos, é possível expandir com mais detalhamento as suas trajetórias biográficas e atrelá-las aos eventos da trama, obtendo, dessa forma, uma visão completa (e complexa) da história.

6.16 Por exemplo: o protagonismo da narrativa deve ser reconhecido não apenas pelo fato de a personagem principal portar um conflito específico (todas as demais fazem o mesmo), mas por conta da jornada que empreende rumo ao encontro de si mesmo, do apaziguamento de suas questões mais intrínsecas, ao (re) estabelecimento da própria identidade.
6.17 Um vilão, por sua vez, deve ser encarado como uma força que igualmente luta contra os próprios medos e conflitos, hesitando por vezes entre um polo e outro de um frágil (des)equilíbrio emocional. O herói, ao se confrontar com essa força, sofre os efeitos que o desestabilizam profundamente e o levam a agir por vezes de forma irracional. É por conta dessa oscilação entre desejos e suas chances de concretização que a maioria das personagens atua num registro camaleônico, assumindo diferentes papéis ao longo dos eventos da narrativa.

6.18 Quanto às etapas da jornada do herói, elas se tornam decisivas para a assimilação da estrutura em três atos. Assimilar a trajetória de um protagonista como uma jornada através de etapas definidas e sucessivas, nas quais os riscos vão se agravando, auxilia a planejar com cuidado os eventos da história e a intensidade de sua progressão.

6.19 A jornada proporciona um discernimento maior a respeito do funcionamento da estrutura e permite encará-la não como uma fórmula, uma unidade estática ou um esquema - e, aqui, retornamos ao conceito de $\sigma \chi \eta \mu \alpha$, de Barthes, vital para a compreensão de seu discurso amoroso -, mas em seu sentido vivo, animado, a serviço das figuras, das ideias, das forças que movem as personagens, e, consequentemente, a história.

\section{Referências}

ANDRADE, Carlos Drummond de. As impurezas do branco. São Paulo: Companhia das Letras, 2012. $168 \mathrm{p}$. 
BARTHES, Roland. Fragmentos de um discurso amoroso. Trad. Hortênsia dos Santos. 13. ed. Rio de Janeiro: Francisco Alves, 1994. 202 p.

CAMPBELL, Joseph. O herói de mil faces. Trad. Adail Ubirajara Sobral. 10. ed. São Paulo: Cultrix/ Pensamento, 2005. $416 \mathrm{p}$.

DURAND, Gilbert. As estruturas antropológicas do imaginário: introdução à arquetipologia geral. Trad. Hélber Godinho. 3. ed. São Paulo: Martins Fontes, 2002. $551 \mathrm{p}$.

ELIADE, Mircea. Mito e realidade. Trad. Pola Civelli. São Paulo: Perspectiva, 1972. 183 p.

HOWARD, David \& MABLEY, Edward. Teoria e prática do roteiro. Trad. Beth Vieira. São Paulo: Globo, 2005. 403 p.

JAMES, Henry. A arte da ficção. Trad. Daniel Piza. São Paulo: Novo Século, 2011. 129 p.

. A arte do romance: Antologia de prefácios. Organização, tradução e notas de Marcelo Pen. São Paulo: Globo, 2003. 319 p.

$\mathrm{KOCH}$, Stephen. Oficina de escritores: um manual para a arte da ficção. Trad. Marcelo Dias Almada. São Paulo: WMF Martins Fontes, 2008. $297 \mathrm{p}$.
McKEE, Robert. Story: Substância, estrutura, estilo e os princípios da escrita de roteiro. Trad. Chico Marés. Curitiba: Arte \& Letra, 2006. 432 p.

MELLO, Ana Maria Lisboa de. Poesia e imaginário. Porto Alegre: EDIPUCRS, 2002. 263 p.

PALLOTTINI, Renata. Dramaturgia: A construção da personagem. 2. ed. São Paulo: Perspectiva, 2013. 232 p.

SALLES, Cecília de Almeida. Gesto inacabado: processo de criação artística. 6. ed. São Paulo: Intermeios, 2013. $186 \mathrm{p}$.

SHEPPARD, David. Novelsmithing: The structural foundation of plot, character and narration / The psychic origins of myth, and mythic origins of storytelling. Healdsburg: Tragedy's Workshop, 2009. 233 p.

VOGLER, Christopher. A jornada do escritor: Estrutura mítica para escritores. 3.ed. Trad. Petê Rissatti. São Paulo: Aleph, 2015. 488 p.

ZAPATA, Ángel. La práctica del relato: Manual de estilo literario para narradores. Madrid: Talleres de Escritura Creativa Fuentetaja, 1997. 227 p.

Recebido: 14 de julho de 2017. Aceite: 7 de dezembro de 2017. 